\title{
ON PROPERTIES OF CONTRACTIONS AND NONEXPANSIVE MAPPINGS ON SPHERICAL CAPS IN HILBERT SPACES
}

\author{
KRZYSZTOF BOLIBOK* AND MARIUSZ SZCZEPANIK** \\ * Stanislaw Staszic High School, Al. Raclawickie 26, 20-043 Lublin, Poland \\ E-mail: kmbolibok@gmail.com \\ **Institute of Mathematics, Maria Curie-Skłodowska University, 20-031 Lublin, Poland \\ E-mail: szczepan@hektor.umcs.lublin.pl
}

Abstract. Let $H$ be an at least two-dimensional real Hilbert space with the unit sphere $S_{H}$. For $\alpha \in[-1,1]$ and $n \in S_{H}$ we define an $(\alpha, n)$-spherical cap by $S_{\alpha, n}=\left\{x \in S_{H}:\langle x, n\rangle \geq \alpha\right\}$. We show that the distance between the set of contractions $T: S_{\alpha, n} \rightarrow S_{\alpha, n}$ and the identity mapping is positive iff $\alpha<0$. We also study the fixed point property and the minimal displacement problem in this setting for nonexpansive mappings.

Key Words and Phrases: Contractions, nonexpansive mappings, fixed point property, almost fixed point property, minimal displacement.

2010 Mathematics Subject Classification: 47H09, 47H10.

Acknowledgment. The authors are grateful to Professor Kazimierz Goebel for valuable comments and suggestions.

\section{REFERENCES}

[1] S. Banach, Sur les opérations dans les ensembles abstraits et leur applications aux équations intégrales, Fundam. Math., 3(1922), 133-181.

[2] M. Baronti, E. Casini, C. Franchetti, The retraction constant in some Banach spaces, J. Approx. Theory, 120(2003), 296-308.

[3] Y. Benyamini, Y. Sternfeld, Spheres in infinite-dimensional normed spaces are Lipschitz contractible, Proc. Amer. Math. Soc., 88(1983), 439-445.

[4] K. Bolibok, Minimal displacement and retraction problems in infinite-dimensional Hilbert spaces, Proc. Amer. Math. Soc., 132(2004), no. 4, 1103-1111.

[5] L. E. J. Brouwer, Über Abbildungen vom Mannigfaltigkeiten, Math. Ann., 71(1911), 97-115.

[6] R. Fleming, J. Jamison, Isometries on Banach Spaces: Function Spaces, Chapman \& Hall/CRC, Boca Raton, 2003.

[7] K. Goebel, On the minimal displacement of points under lipschitzian mappings, Pacific J. Math., 45(1973), 151-163.

[8] K. Goebel, W.A. Kirk, Topics in Metric Fixed Point Theory, Cambridge University Press, Cambridge, 1990. 
[9] M.D. Kirszbraun, Über die zusammenziehende und Lipschitzsche Transformationen, Fund. Math., 22(1934), 77-108.

[10] T. Komorowski, J. Wosko, A remark on the retracting of a ball onto a sphere in an infinite dimensional Hilbert space, Math. Scand., 67(1990), 223-226.

[11] B. Nowak, On the Lipschitz retraction of the unit ball in infinite dimensional Banach spaces onto boundary, Bull. Acad. Polon. Sci., 27(1979), 861-864.

[12] F.A. Valentine, A Lipschitz condition preserving extension for a vector function, Amer. J. Math., 67(1945), 83-93.

Received: April 30, 2015; Accepted: October 8, 2015. 